development of the icosasphere, a new type of spherical tank, and research continued on components for supersonic wind tunnels, as well as on the 'Stypol' resins, a series of liquid thermosetting materials devised by the Robertson multiple fellowship on protected metals. Research was started on the chemistry of the nickel sulphides, and the multiple fellowship on coal-waste control has recommended methods of constructing refuse piles that assure a desired degree of resistance to spontaneous, incidental or deliberate ignition and has studied in the field a number of methods of extinguishing refuse fires.

The multiple fellowship on acid recovery has extended its scope to include the investigation of other wastes from the manufacture of steel, besides spent pickle liquor, and a survey of literature on the toxicity to aquatic and animal life of substances in streams and on tastes and odours has induced an investigation to determine whether a balance between phenol-consuming and phenol-producing organisms can result in a phenol equilibrium concentration. The chemical potentialities of pyridine were being studied, as well as the development of methods for the treatment and disposal of industrial wastes, the utilization of the ethylbenzene in aromatic petroleumnaphtha fractions for the manufacture of styrene, and the suitability of plastic pipe in a low-pressure distribution system for natural gas. A study of the kinetics of the oxidation of lubricating oil has been leading to new concepts of the function of additive materials in the process, and work on hydrocarbon synthesis over catalysts of the iron group was being completed. Much effort was being given to the development of analytical techniques for detecting and determining the sulphur compounds of petroleum. Work continued on the composition of petroleum waxes and the relation between their composition and physical and engineering properties, and a theory has been formulated which relates the solubility of a gas in wax to the critical constants of both solvent and gas.

A ehemical study of the pyrrole pigments and their relations to the chlorophylls and hæmins was resumed, while that of the chemical composition of petroleum waxes and petrolatums led to the devising of special analytical techniques for measuring the physical properties of small fractions. Further detailed research was conducted on the factors affecting absorbent efficiency in cane-sugar refinery operations, and experiments on the variation in composition of gases dissolved in purée fruit and vegetable products over prolonged storage confirmed that a fundamental reaction in discoloration is oxidation. Most of the end-products of the discoloration of fruit and vegetables are small enough to go through a dialysis membrane. Compositions containing piperonyl butoxide have now been shown to be safe and effective additions for protecting grain and other stored products from infestation by insects. Zein emulsions have been obtained which possess low viscosity at high solid content and yield films comparable in clarity, gloss and resistance to water to coatings obtainable from alcoholic solutions. Investigations of industrial fabrics have centred on the improvement of dimensional stability and resistance to heat, water and chemicals, and those on alkyd resins indicate the value of $1: 3$-dimethyl-2-hexenolide as component. Work on the utilization of non-ionic surfaceactive agents has progressed, and much was done on test methods for evaluating soil conditioners and on the utilization of vinyl resins and silicones.

\section{ROTHAMSTED EXPERIMENTAL STATION REPORT FOR 1953}

$I^{\mathrm{N}}$ the annual report for 1953 of the Rothamsted Experimental Station*, it is apparent to the most casual reader that the research staff of the Station have been by no means idle during the year covered by the report. The rapid expansion in the scope of Rothamsted's activities since the Second World War-there are at present approximately three hundred and seventy people actively engaged in research and administration - has necessitated an active building programme, and several new buildings are being provided to meet the more pressing needs for accommodation.

In the Chemistry Department the assessment by laboratory and field tests of the agricultural value of water-insoluble phosphates is receiving attention in view of the attempts made by manufacturers to economize in the use of sulphuric acid for phosphatic fertilizer production. In general, the outstanding merits of water-soluble phosphates on most classes of land have again been evident, particularly when used as a starter dose placed close to the-seed; but on some soils and with certain crops, various forms of insoluble phosphates have yielded results comparable to superphosphate. On all classes of soil, with potatoes and swedes, dicalcic phosphate in finely divided form gave results only slightly inferior to superphosphate; silicophosphate gave good results with potatoes on very acid soils, but was markedly less effective on moderately acid and neutral soils. On the other hand, 'Gafsa' phosphate was ineffective for potatoes on even very acid soils. All three forms gave good results with swedes. Experiments with nitro-phosphates indicate that the phosphate in these compounds has a value akin to that in high-soluble basic slags.

Work on fertilizer placement with potatoes indicates that with moderate dressings better results follow when the fertilizers are placed than when broadcast; the reverse is the case when heavy dressings are applied. With horticultural cropslettuce, cabbage, beetroot, broad beans and runner beans-better results are obtained by placement of fertilizer.

In the Physics Department, work on the crumb structure of soils continues, and a technique for measuring the resistance of crumbs to dispersion developed. Using this technique on grass and lucerne plots sited on a field that had been under arable cultivation for many years, it has been established that two to four years under grass has materially improved the cohesion of the surface crumbs. By using a deep-rooted erop to dry out the subsoil during the summer, the permeability of heavy clay soils during the winter months may be improved, a point of practical importance to those concerned with drainage of heavy clay soils.

A simple method for measuring the deficit of divalent ions in soils flooded by sea water has been devised and will be used for estimating the dressings of gypsum needed on such land to prevent breakdown of crumb structure during the next few years.

The production of antibiotics in the soil by certain Actinomycetes and their influence on combating

* Report of the Rothamsted Experimental Station for 1953. Pp. 
root-infecting fungi is being studied by the Soil Microbiology Department. Such antibiotics tend to be adsorbed and rendered inactive by certain soil constituents, particularly the clay fraction, and attempts are being made to ascertain which Actinomycete antibiotics are least affected in this way and to measure their activity in various types of soil. Pot experiments have definitely confirmed that root rot by Helminthosporum sativum is significantly reduced by some of the Actinomycete strains.

The work on the nodule organisms of legumes has reached an interesting stage. The number of nodules developing on the root is apparently determined more by the susceptibility of the root to infection than by the population of the nodule bacteria surrounding it, and in the case of clover it has been shown that hereditary factors influence the time at which the nodules first appear, the number of nodules produced and their effectiveness in fixing nitrogen.

In the Botany Department it has been established that some of the ill effects of excess of manganese, vanadium and molybdenum may be prevented by increasing the supply of iron, and farmers troubled with wild oat infestation will learn with interest that the sowing of winter corn instead of spring corn will result in lessened germination, and production, of new seeds by this plant pest.

Heat therapy as an aid in the control of plant viruses has received the attention of the Plant Pathology Department, with variable results. It would appear that viruses of spherical shape are inactivated by heat treatment but not rod-shaped viruses. Much information on other aspects of virus infection is contained in the report.

The study of enzyme action is the main concern of the Biochemistry Department. Special attention is being paid to ribonuclease in view of the fact that every plant virus hitherto obtained in a pure state has proved to be a ribonucleoprotein. Oxidative enzymes are also being studied, since plant hormones and growth regulators are subject to enzymatic oxidation, and such enzymes by their effect on the concentration of these substances may play a. part in the regulation of plant growth. The enzymic breakdown of cellulose and chitin is also receiving attention.

Eelworms, which are becoming an increasing menace to cereal and potato growers, are being intensively studied by the Nematology Department. In attempts to combat this pest, endeavours have been made to discover resistant crop varieties and suitable crop rotations for infected land. One spring and two or three winter oat varieties appear to be resistant to stem eelworm attack, but no commercial variety of potato resistant to potato tuber eelworm was discovered. Attempts are being made to obtain resistant varieties by crossing commercial strains with Solanum indigenum, which is resistent to eelworm attack. Work is also in progress on root diffusates which stimulate the hatching of eelworm cysts, and on the control of eelworm by the application of chemicals to infested soils.

In the Entomology Department the work on insect migration, on the influence of weather on insect populations, on gall midges of economic importance and on aphid problems has continued. Three points of interest may be singled out: lepidopterous larvæ apparently develop and grow more rapidly when crowded together than when solitary ; aphids do not normally reproduce unless they have previously made a flight, however brief; and wheat bulb flies have been successfully bred under laboratory conditions.
The Bee Department's report contains much of importance to apiarists. The fumes produced by adding small quantities of ammonium nitrate to burning smoker fuel provide a simple anæsthetic for use when transferring bee colonies from one site to another a short distance away, since on recovery the bees lose their tendency to drift back to the original site. The known ability of worker bees to cluster together when dispersed in an area in total darkness is associated with their search for warmth and food, and, if a queen is present, for 'queen substance'. Queen honey bees secrete on all parts of their bodies this 'queen substance' which is eagerly sought for by the worker bees, and is considered to be most important in the maintenance of colony cohesion. A temporary shrortage of supply of this substance or a breakdown in its distribution leads to toleration by the workers of eggs and larvæ in the queen cup cells and a consequent tendency to swarm. The report contains suggested rules, based on this work, to be followed when introducing to colonies mated queens of any age or strain.

The Insecticides and Fungicides Department has continued its work on particle size and toxicity of suspensions of contact insecticides, and on insect esterases and their inhibition by organo-phosphorus compounds. The work on the relationship between the insecticidal activity and the chemical constitution of pyrethrin-like compounds has now reached an important stage. By means of displacement chromatography four known active constituents have been separated from each other and from some inactive constituents of pyrethrum extract, and their relative toxicities compared. The report also contains much useful information on bioassay techniques, toxicity-persistence of insecticidal deposits, the mechanism of the selection of strains of insects resistant to insecticides, and, in the field, on the control of Aphis faboe on field beans, control of the vectors of potato virus and control of wireworms.

\section{CITY MUSEUM, BRISTOL REPORT FOR 1953}

$T$

HE two well-produced and excellently illustrated booklets*- the annual report of the City Museum, Bristol, for 1953 and the new handbook to Stratford Mill in Blaise Castle House Folk Park-bear unmistakable testimony to that invaluable tripartite combination, an appreciative committee, an understanding and far-seeing director and a loyal and enthusiastic staff.

The inside of the cover of the Museum report details activities and offerings of specimens, collections and services of which Bristol can justly be proud, and the report shows the gratifying and growing response received. The main duty of the Museum is rightly taken to be the portraying of local history and local natural history, and the commendable progress made is recorded in the succeeding departmental reports. Rearrangement of the collections is being made to bring the exhibition series into accord with both modern scholarship and contemporary museum display methods. The new

* City Museum, Bristol. Report of the Committee for the Year ended 31 December, 1953. Pp. $16+2$ plates.

Stratford Mill in Blaise Castle House Folk Park. Pp. $8+2$ plates. $6 d$. (Bristol: City Museum, 1954.). 